\title{
Estado e Terceiro Setor: Um caso de complementação ou substituição?
}

\author{
State and Third Sector: A case of complementation or replacement? \\ Estado y Tercer Sector: ¿Un caso de complementación o sustitución?
}

Recebido: 07/01/2021 | Revisado: 08/01/2021 | Aceito: 09/01/2021 | Publicado: 10/01/2021

\author{
Raquel da Silva Moreira \\ ORCID: https://orcid.org/0000-0003-1372-9784 \\ Marinha do Brasil, Brasil \\ E-mail: raquel.moreira@marinha.mil.br
}

\begin{abstract}
Resumo
O presente artigo é fruto de estudo que visa refletir sobre a resposta do Estado neoliberal frente às demandas por políticas sociais, e como ocorre a transferência de responsabilidade para a sociedade civil em prover ações para efetivar direitos sociais. A sociedade civil por sua vez vem se organizando e profissionalizando para responder tal demanda, ainda que de forma pontual e seletiva. Diante desse cenário ficam as inquietações: como o Estado tem assumido a responsabilidade de prover políticas públicas na área social? As instituições do terceiro setor conseguem cumprir integralmente a função que lhe é transferida? A pesquisa foi realizada por levantamento e estudo de bibliografias nas áreas de políticas sociais, estado neoliberal e terceiro setor. Tal estudo foi basilar para análise da atuação de instituições da sociedade civil com programas sociais em suas frentes de trabalho. O estudo nos revela que a responsabilidade do Estado na provisão de políticas sociais é transferida à sociedade civil sob uma roupagem de papel complementar, mas na prática o que ocorre é a terceirização de papéis, já que para os neoliberais a intervenção estatal deve ser mínima na área social.
\end{abstract}

Palavras-chave: Papel do Estado; Terceiro Setor; Direitos Sociais.

\begin{abstract}
This paper is the result of a study that aims to reflect on the response of the Neoliberal State to the demands for social policies, and how responsibility is transferred to civil society regarding the provision of actions to enforce social rights. Civil society, in turn, has been organizing and professionalizing to respond to such demand, although punctually and selectively. Faced with this scenario, concerns arise: how has the State taken responsibility for providing public policies in the social area? Are Third Sector institutions able to fully fulfill the function transferred to them? The research was carried out by data survey and study of bibliography in the following areas: Social Policies, Neoliberal State, and Third Sector. This study was essential for analyzing the performance of civil society institutions with social programs on their work fronts. The study reveals that the responsibility of the State in providing social policies is transferred to civil society as a complementary role, but what occurs is the outsourcing of roles, since, for neoliberals, State intervention in social areas must be minimal.
\end{abstract}

Keywords: State Role, Third Sector, Social Rights.

\section{Resumen}

Este artículo es el resultado de un estudio que tiene como objetivo reflexionar sobre la respuesta del Estado neoliberal a las demandas de políticas sociales y cómo se da la transferencia de responsabilidad a la sociedad civil en la provisión de acciones para la efectividad de los derechos sociales. La sociedad civil, a su vez, se ha ido organizando y profesionalizando para responder a tal demanda, aunque de manera puntual y selectiva. Ante este escenario surgen las inquietudes: ¿cómo se ha responsabilizado el Estado de impulsar políticas públicas en el ámbito social? ¿Pueden las instituciones del tercer sector cumplir plenamente la función que se les transfiere? La investigación se realizó mediante recopilación de datos y estudio de bibliografías en las áreas de políticas sociales, estado neoliberal y tercer sector. Este estudio fue fundamental para analizar el desempeño de las instituciones de la sociedad civil con programas sociales en sus frentes de trabajo. El estudio revela que la responsabilidad del Estado en la provisión de políticas sociales se transfiere a la sociedad civil como un rol complementario, pero en la práctica lo que ocurre es la tercerización de roles, ya que para los neoliberales la intervención estatal debe ser mínima en el área social.

Palabras clave: Rol del Estado; Tercer Sector; Derechos Sociales.

\section{Introdução}

A garantia das condições mínimas de bem estar social é atualmente transferida à sociedade civil organizada, assim como foi a provisão de direitos sociais como saúde, educação, habitação, saneamento básico, entre outros, livre à iniciativa 
privada. Tal movimento traz consigo vantagens superficiais e contrariedades que geram novos contornos a administração do espaço público não estatal e das políticas sociais no neoliberalismo.

Outro aspecto para reflexão crítica é observar se a terceirização na provisão de direitos sociais impacta de alguma forma na superação da suposta crise econômica do Estado.

A constituição do Terceiro Setor como alternativa à crise e suposta ineficiência do Estado máscara ideologicamente a real crise, que é intrínseca ao sistema capitalista.

Estas reflexões estão longe de dar uma resposta definitiva às muitas metamorfoses do sistema capitalista como forma de tentar conformar e amenizar os conflitos gerados pela exploração do trabalho pelo capital.

\section{Metodologia}

A metodologia de pesquisa utilizada adota a abordagem qualitativa; que em geral, ocorre no ambiente natural com coleta direta de dados e o pesquisador é o principal instrumento (Ludke \& André, 2013) e o estudo de caso (Yin, 2001).

Além disso, o levantamento bibliográfico é o ponto de partida para qualquer tipo de pesquisa, facilitando a investigação através do estudo do conhecimento acumulado e armazenado em livros, artigos e documentos. Aliado ao estudo de conhecimento teórico acumulado, a análise qualitativa do fenômeno social em questão nesse artigo utilizou uma abordagem empírica, onde o pesquisador necessita da observação dos fatos, assim como anotá-los. Em seguida, usando como critério os informes colhidos por meio dos sentidos e a partir de particularidades ou detalhes, terá como comparar os resultados da observação de alguns casos com o conjunto dos casos possíveis, para assim formular conclusões (Alyrio, 2009).

A coleta de dados da pesquisa foi realizada em uma instituição do terceiro setor, Instituto Jelson da Costa Antunes (IJCA), que tem como frentes de trabalho programas sociais voltados à educação profissionalizante, educação básica e empreendedorismo de jovens oriundos de comunidades dos municípios de São Gonçalo, Niterói, Itaboraí e Maricá, na região metropolitana do Rio de Janeiro.

Nos tópicos seguintes são apresentadas as reflexões sobre o papel do Estado no Capitalismo, em particular, no estágio neoliberal, o surgimento do terceiro setor e a gradual transferência de responsabilidade das políticas sociais para a sociedade civil, além de um panorama geral desta, e as considerações finais apresentando o encerramento do resultado da análise.

\section{Resultados e Discussão}

\section{Papel do Estado no Capitalismo}

Após o advento da Revolução Industrial, o Estado liberal, baseado na economia de mercado e modelo de produção fordista, passou por pressões em função da forma como os trabalhadores se mobilizavam por melhores condições de vida. Naquele momento, as demandas sociais se tornavam cada vez mais intensas, tamanho era o grau de exploração dos trabalhadores, com jornadas de trabalho elevadas e baixos salários, assim como insalubridade e ausência de políticas que assegurassem um mínimo de qualidade de vida.

Nesse contexto, a intervenção do Estado nas questões sociais, a fim de controlar e amenizar as reivindicações dos trabalhadores tornou-se imprescindível. Para garantir a manutenção do poder vigente, o liberalismo teve que assumir a possibilidade de convivência com a implantação de políticas sociais para conter a forte organização dos trabalhadores. A partir daí, as políticas de proteção social deixaram um pouco o caráter assistencialista de controle da miséria para se configurar na perspectiva de um modelo de garantia de direitos sociais, o Welfare State.

Nos fins do século XIX, prevaleceu de fato um conjunto de fatores econômicos, sociais e políticos favoráveis à construção de um moderno conceito de proteção social. E este conceito, ao associar bem-estar à cidadania, expressou 
verdadeiramente um padrão de regulação sócio-econômico avesso ao paternalismo, passando a ser visto como o início do Welfare State (Pereira, 2008: 34).

O padrão de proteção social difere de país para país, correspondendo aos contextos históricos e ideológicos. Porém, a concepção básica é a "garantia de niveis de renda e acesso a recursos e serviços básicos, afastando a possibilidade de queda numa pobreza extrema, no abandono e no desabrigo" (Pereira, 2008: 178).

Cabe destacar que o Estado, nesse modelo, é o principal executor das políticas econômicas e sociais, ficando sob sua responsabilidade a tarefa de proporcionar o bem estar e a garantia de condições de vida aos trabalhadores. Essa atribuição não se dá de forma natural, houve luta e pressão por novas condições de vida que permitissem usufruir de direitos.

O pensador do Welfare State foi John Maynard Keynes que idealizou que só seria possível a manutenção do sistema capitalista com ações do Estado voltadas ao equilíbrio das relações entre capital e trabalho. A regulação do mercado teria papel fundamental no conjunto de medidas propostas por Keynes, pois, ao contrário da teoria dominante da época que defendia que a liberdade completa do mercado daria a direção à sociedade; um Estado interventor estaria muito mais capacitado para evitar a crise de um sistema socioeconômico contraditório e desigual.

Keynes não pretendia conter a evolução do modo de produção capitalista, muito menos promover sua eliminação, mas sim socializar o consumo. Essa perspectiva implica em limites a esse plano, apesar de ser um avanço no que diz respeito ao progresso pelas lutas da classe operária em conquistar direitos sociais. (Pereira, 2008)

Com as diversas crises econômicas dos anos 70 e 80, (com forte destaque a queda no preço do petróleo, desestabilizando os mercados mundiais) as políticas sociais na Europa, provenientes do padrão keynesiano de proteção social, sofreram fortes impactos.

O discurso predominante era de que sua sustentação havia se tornado um peso para o Estado, deslegitimando assim as conquistas sociais alcançadas e reduzindo drasticamente seu papel de provedor.

Assim, diante das alterações nas funções do Estado diante das crises provocadas pelo sistema econômico, o neoliberalismo surge como alternativa das elites mundiais para a superação da crise.

Podemos definir o neoliberalismo como um conjunto de ideias políticas e econômicas capitalistas que defende a não participação do estado na economia. De acordo com esta doutrina, deve haver total liberdade de comércio (livre mercado), pois este princípio garante o crescimento econômico e o desenvolvimento social de um país. (Ramos, 1994)

As principais características do modelo neoliberal são:

- mínima participação do Estado na economia de um país;

- pouca intervenção do governo no mercado de trabalho;

- política de privatização de empresas estatais;

- livre circulação de capitais internacionais;

- Ênfase na globalização;

- Abertura da economia para as multinacionais;

- diminuição do tamanho do Estado, tornando-o mais forte;

- aumento da produção objetivando atingir o desenvolvimento econômico;

- a lei da oferta e da procura é suficiente para regular os preços;

- a base da economia deve ser formada por empresas privadas;

- defesa dos princípios econômicos capitalistas. 
Os países subdesenvolvidos vivenciaram o rebatimento dessa nova política somente na década de 90, apesar do Welfare State ter tido pouco ou quase nenhum alcance nessas regiões.

A redefinição das atribuições do Estado teve consequências diversas, porém o foco principal desse estudo foi a transferência por parte do Estado na execução de atividades ligadas a políticas sociais para associações privadas sem fins lucrativos.

Para a efetivação de um projeto que "flexibiliza" a obrigatoriedade do Estado em assumir o papel principal na promoção de políticas públicas, principalmente as sociais, a sociedade civil foi convocada a trabalhar em ações sociais, movidas por um espírito de colaboração e solidariedade, expressa principalmente pela via do voluntariado. Nesse momento é inaugurado o chamado Terceiro Setor como via mantenedora de um modelo de proteção social nos moldes neoliberais.

O termo Terceiro Setor surgiu nos EUA, na transição dos anos 70 para os 80 , e foi criado pretensamente para resolver a dicotomia entre o público e o privado, onde o público é identificado como Estado e o privado como Mercado. Se o Estado está em crise e o Mercado tem interesses lucrativos, não havia espaço para oferta de respostas às demandas sociais. Então, o Terceiro Setor passa a ser compreendido como a atividade pública desenvolvida pelo setor privado, ou então, o público não estatal.

Vale destacar a Constituição de 1988, que num amplo processo de mobilização social, garantiu formalmente um aumento dos direitos, sendo eles sociais, políticos e econômicos.

Constata-se nas últimas décadas um crescimento quantitativo e qualitativo das organizações que compõem o Terceiro Setor, em especial das ONGs (Organizações-Não-Governamentais) que em sua origem traziam um cunho político de luta por direitos.

Até mesmo o Segundo Setor, que funciona na lógica de obtenção de lucro, já a partir da década de 90, destina recursos para programas e projetos sociais, especialmente, através de suas fundações e institutos, sendo assim mais uma forma de organização no Terceiro Setor.

A partir dos anos 90, como já citado, o ajuste neoliberal gerou enormes consequências para a política social, pois por décadas o Estado se comportou como provedor de bens e serviços públicos, com características de Estado Máximo e no final do século passado, observa-se que o papel do Estado tomou um movimento diferenciado, no qual, passou a exercer cada vez mais a sua função de regulador e cada vez menos a função de provedor. Vários fatores contribuíram para essa nova função do Estado, como a globalização financeira, a abertura comercial, a constante privatização de empresas públicas, a formação de blocos regionais e o fortalecimento dos poderes locais.

A questão principal da transformação do Estado Provedor para o Estado Regulador reside em esclarecer que o caráter público de uma instituição sem fins lucrativos não pode ser confundido com a transferência de um serviço que é de função do Estado para uma organização privada não-lucrativa, de natureza voluntária, e, portanto, não se configura em garantia de direito.

O caráter "complementar" dos serviços sociais ofertados por organizações do terceiro setor já aponta para a idéia de que o Estado, no formato atual, é incapaz de garantir os direitos previstos constitucionalmente de maneira efetiva, já que se todas as suas atribuições fossem devidamente exercidas, não haveria necessidade de terceirizá-los.

Poderíamos considerar um programa social na área de educação, financiado por um grupo empresarial como uma política pública social? Deveríamos entender que na idealização desse programa social, incentivado por motivações pessoais de ajuda aos mais pobres, haveria uma sugestão de que se o Estado não garante uma educação de qualidade, logo terceiros deveriam garantir? 


\section{Crise de legitimidade do Estado e Terceiro Setor}

A passagem da responsabilidade estatal para a sociedade civil gera a perda da concepção de direito, principalmente, por parte dos próprios usuários das políticas sociais.

O Terceiro Setor através de suas ações fragmenta o tratamento da "questão social". Isso ocorre porque as organizações do Terceiro Setor atuam em pequenas áreas de abrangências, não podendo compensar em qualidade, quantidade, variedade e abrangência as políticas sociais abandonadas pelo Estado (Bresser Pereira apud Montaño, 2008).

Outro grande problema é o enfraquecimento das reivindicações e das lutas de classe, onde o indivíduo não se vê como classe, ainda que reconheça sua situação pauperizada. Então, ao priorizar as ações da sociedade civil, anula-se o processo democrático, ou seja, a contradição capital/trabalho é substituída pela parceria entre classes de interesses comuns; no lugar da superação da lógica capitalista tem-se a naturalização e a humanização da mesma.

As organizações do terceiro setor assumem um caráter de privatização da coisa pública, pois sua iniciativa pela prestação de um determinado serviço depende da prontidão do indivíduo e da conjuntura governamental, pois em algumas instituições, existe a relação de dependência ao governo devido a necessidade de conseguir financiamento para um determinado projeto; onde a capacidade de "conquistar" patrocinadores passa a ser fundamental para a sobrevivência da instituição e de seus serviços; onde a caridade, através do voluntariado, representa a única chance, muitas vezes, de manter a instituição aberta.

Esse é um exemplo de que, se o terceiro setor exercesse um papel complementar em relação às políticas sociais promovidas pelo Estado, esse garantiria sua manutenção e o que se percebe é o movimento contrário, na qual muitas das ações do terceiro setor vêm fazer o papel das políticas de forma não sistemática e sem controle por parte do Estado. Isso não significa que esse setor não esteja profissionalizado e organizado, muito em decorrência da complexidade que as demandas sociais tomaram.

Utilizando a análise de Montaño (2008), as organizações sem fins lucrativos recebem por parte do Estado a concessão para criar, gerenciar e atuar sobre uma determinada realidade social. Neste sentido, todo trabalho com intenção de superar as seqüelas da questão social, será exercido por uma instituição ou por grupo organizado.

As políticas sociais se apresentam, após seu redirecionamento à iniciativa privada, como políticas que não atendem ao caráter universal de atendimento e acesso dos cidadãos. Como explica Pereira (2008), as políticas focalizadas que são elaboradas de forma vertical, sem critérios de participação nas decisões e construção de alternativas para solucionar as demandas e necessidades sociais que se apresentem, não atendem aos requisitos de uma política voltada para a promoção de bem-estar comum e universal, mas de forma funcional atacar um determinado problema, nem sempre com a possibilidade de resolução.

Política Social refere-se à política de ação que visa, mediante esforço organizado e pactuado, atender necessidades sociais cuja resolução ultrapassa a iniciativa privada, individual e espontânea, e requer deliberada decisão coletiva regida por princípios de justiça social que, por sua vez, devem ser amparados por leis impessoais e objetivas, garantidoras de direitos (Pereira, 2008).

Assim, as políticas sociais conduzidas pela organização privada, com ou sem fins lucrativos, não atendem aos requisitos para que sejam garantidos direitos, mas conta-se com a eventualidade e imprevisibilidade, primeiro, do surgimento de uma instituição que assuma determinado postulado; segundo, pela capacidade dependente de auxilio fora da instituição; terceiro, pela decisão da direção ou gerência da organização, que utiliza de critérios dentro do possível para cumprir os objetivos aos quais ela se propôs. Mais ainda, o curto alcance das políticas sociais no âmbito de instituições não-lucrativas têm 
firme sustentação quando se percebe que para seu financiamento necessariamente deixam-se outras de fora, sob as mais diversas justificativas, mas que na verdade têm uma só razão de ser: a transferência de responsabilidades e a desfiguração do conceito de política social.

\section{Dados sobre o terceiro setor hoje}

Em função do crescimento do Terceiro Setor na década de 90, houve a premente necessidade de leis adequadas, tamanha a sua importância e expansão na nossa sociedade. A lei até então vigente, o Código Civil de 1917, já estava ultrapassada.

A partir de 1990 várias leis foram aprovadas, regulamentando o exercício do terceiro setor. Como exemplo, citamos a Lei Federal n. ${ }^{\circ}$ 9.790/99, que dispõe sobre a qualificação de pessoas jurídicas de direito privado, sem fins lucrativos, como Organização da Sociedade Civil de Interesse Público, institui e disciplina o Termo de parceria. Temos também a Lei Federal $n^{\circ}$ 9.608/98 que dispõe sobre o serviço voluntário.

Recentemente tramitou no Senado e no Congresso diversos projetos de lei que tratam de assuntos relacionados às organizações do terceiro setor (como alteração do regime fiscal e tributário e a ampliação da fiscalização por parte do poder público) fomentando a parceria entre governo e sociedade civil em várias áreas, ampliando as possibilidades de doações as organizações e até criando um programa nacional de apoio e fortalecimento econômico das entidades do terceiro setor.

Diversas organizações como a Associação Brasileira de organizações não-governamentais (ABONG), a Rede de Informação do Terceiro Setor (RITS) e o Grupo de Institutos, Fundações e Empresas (GIFE), entre outras acompanham essas propostas e divulgam informações específicas sobre o setor.

Existem diversas formas jurídicas e títulos direcionados especificamente para as entidades do terceiro setor, a legislação brasileira permite que se organizem (segundo critérios específicos) em:

- Associação

- Fundação

- Organizações religiosas

- Utilidade pública federal

- Organizações da Sociedade Civil de Interesse Público (OSCIP)

Alguns necessitam obter registro no Conselho Nacional de Assistência Social (CNAS) e Certificado de Entidade Beneficente de Assistência Social (CEBAS).

Pesquisas sobre o setor foram realizadas pela Associação Brasileira de Organizações Não-Governamentais (ABONG), entidade que congrega as maiores ONGs do país. O estudo desenvolvido em $2001 \mathrm{com} 196$ ONGs associadas revela quais setores recebem maior atenção. A principal área de atuação do terceiro setor se localiza na educação com 52,0\%, podendo atuar eventualmente em outras áreas de forma conjunta.

A educação e qualificação profissional são prioridades no investimento do empresariado. O principal motivo apontado é de que:

"a educação é uma área considerada "não-assistencialista" e "não paliativa" e sim uma área que produz um "retorno" para a sociedade. Esta ideia está em consonância com o conceito de desenvolvimento sustentável, na medida em que contribui não só para a geração presente, como também para a geração futura.” (ABONG, 2000).

Podemos constatar, segundo Rico (2001): “Os empresários cidadãos se inserem na comunidade investindo recursos próprios, que possam trazer resultados concretos para a população local e que tenham possibilidade de auto-sustentabilidade e multiplicação." 
Considerando também que a área da educação traz consigo a crença de que a transformação social se faz através dela, e que por isso, é uma categoria que gera impacto e traz resultados de longo prazo.

O estudo aponta também para as instituições que são independentes fisicamente e algumas até financeiramente, devido à captação de recursos externa. Ainda que possua autonomia, estas instituições continuam carregando o nome da empresa que a criou, e em consequência das ações sociais acaba agregando um marketing social positivo para as mesmas.

No que tange à gestão das atividades sociais, os Institutos empresariais são fortemente influenciados por valores empresariais como a eficácia e a eficiência, estabelecimento de metas, racionalização de recursos, gestão de pessoas, entre outros. Essa racionalização dá um tom de "profissionalização" às atividades e isso implica na realização de ações "profissionais" e não "amadoras", dotadas de planejamento e estratégias para obtenção de resultados.

Como aponta Mansur, 2004:

Dessa forma, tendo em vista que a empresa tem como natureza e objetivo a obtenção lucros, na área social, ou seja, o "investimento social" não vai ser diferente. Isto é, ela vai querer ter melhores resultados, ou seja, "lucros", que neste caso não são necessariamente em capital dinheiro diretamente, mas, indiretamente geram-se lucros através da sua imagem positiva.

Outro fator relevante sobre esta questão da profissionalização é a necessidade de ter um quadro de funcionários, ainda que pequeno, extremamente capacitado. Isso porque os funcionários desses institutos e fundações precisam ser tão qualificados quanto os profissionais de uma empresa, já que trabalham sob uma cultura e racionalidade semelhantes.

Sendo assim, os seus funcionários precisam saber elaborar, implementar, liderar e gerenciar equipes e projetos, monitorar e avaliar os mesmos, além de ter uma ágil comunicação com os seus parceiros e as partes envolvidas. Isso quer dizer que essas instituições lidam o tempo todo com diversos tipos de setores, profissionais, pessoas e países, o que exige também o conhecimento de idiomas.

Com a nítida descrença no $1^{\circ}$ setor, onde trabalhar para o Estado significa morosidade e burocracia, falta de recursos e de planejamento. Basicamente, a imagem que se formou foi a de um $1^{\circ}$ setor ineficiente, de um $2^{\circ}$ setor ligado exclusivamente ao lucro e interesses particulares e de um $3^{\circ}$ setor ligado à transformação social e liberdade.

\section{Considerações Finais}

Diante do cenário exposto acima, concluímos que o Estado no atual sistema capitalista neoliberal defende a ideia da privatização e da transferência de suas responsabilidades como provedor de direitos ao Terceiro Setor. Essa transferência de papéis traz consigo a fragilização na concepção de direitos sociais universais, onde os programas e projetos sociais focalizam os direitos a nível local, pois o alcance de uma instituição do terceiro setor não será nunca na mesma proporção de uma política social, nem existe uma padronização na qualidade dos serviços prestados, convivendo ainda em algumas ONG's o retrocesso da refilantropização da "questão social".

Considerando que as instituições sem fins lucrativos prestadoras de serviços em áreas de responsabilidade governamental, promotoras de voluntariado, financiadas pela iniciativa privada ou pelo poder público, através de programas sociais, são entidades úteis para o desenvolvimento local, e contribui para transformação social da realidade de algumas das famílias atendidas, seu alcance e impacto social serão sempre limitados. E apesar do terceiro setor está se desenvolvendo e profissionalizando com equipes qualificadas em ferramentas de gestão empresarial, não deveria substituir a ação estatal com o risco de retrocedermos anos nas conquistas históricas da classe trabalhadora por garantias de direitos. 
Research, Society and Development, v. 10, n. 1, e24610111768, 2021

(CC BY 4.0) | ISSN 2525-3409 | DOI: http://dx.doi.org/10.33448/rsd-v10i1.11768

Pesquisas futuras envolvem o esforço de aprofundar qual é o impacto do trabalho de instituições do terceiro setor na cobertura da falta de políticas sociais. As atividades desenvolvidas alcançam o público alvo de maneira universal ou em larga escala?

\section{Referências}

ABONG, (2000). ONGs Identidades e Desafios Atuais. Autores Associados.

Alyrio (2009). Métodos e técnicas de pesquisa em administração. Fundação CECIERJ.

Mansur (2004). A Ação Social das Fundações e Institutos Empresariais: O Caso do Rio de Janeiro. Dissertação de Mestrado em Serviço Social da Universidade do Estado do Rio de Janeiro.

Montano (2008). Terceiro Setor e questão social: crítica ao padrão emergente de intervenção social. Editora Cortez.

Pereira (2018). Metodologia da pesquisa científica. Ed. UAB/NTE/UFSM.

Pereira (2008). Política social: temas e questões. Editora Cortez.

Ramos (1994). Liberalismo - o que é, origem, resumo das características. Universidade de São Paulo.

Rico (2001). Filantropia Empresarial e a Gestão de Projetos Sociais. Tese de Doutorado da Pontifícia Universidade Católica de São Paulo. 